\title{
The Majority of the Type III Effector Inventory of Pseudomonas syringae pv. tomato DC3000 Can Suppress Plant Immunity
}

\author{
Ming Guo,, ${ }^{1,2}$ Fang Tian, ${ }^{1,3}$ Yashitola Wamboldt, ${ }^{1}$ and James R. Alfano, ${ }^{1,2}$ \\ ${ }^{1}$ The Center for Plant Science Innovation, University of Nebraska, Lincoln, Nebraska 68588-0660, U.S.A.; ${ }^{2}$ Department \\ of Plant Pathology, University of Nebraska, Lincoln, Nebraska 68588-0722, U.S.A.; ${ }^{3}$ School of Biological Sciences, \\ University of Nebraska, Lincoln, Nebraska 68588-0722, U.S.A.
}

Submitted 11 March 2009. Accepted 30 April 2009.

The Pseudomonas syringae type III protein secretion system (T3SS) and the type III effectors it injects into plant cells are required for plant pathogenicity and the ability to elicit a hypersensitive response (HR). The HR is a programmed cell death that is associated with effector-triggered immunity (ETI). A primary function of $P$. syringae type III effectors appears to be the suppression of ETI and pathogen-associated molecular pattern-triggered immunity (PTI), which is induced by conserved molecules on microorganisms. We reported that seven type III effectors from $P$. syringae pv. tomato $\mathrm{DC} 3000$ were capable of suppressing an HR induced by $P$. fluorescens(pHIR11) and have now tested 35 DC3000 type III effectors in this assay, finding that the majority of them can suppress the HR induced by HopA1. One newly identified type III effector with particularly strong HR suppression activity was HopS2. We used the pHIR11 derivative pLN1965, which lacks hopA1, in related assays and found that a subset of the type III effectors that suppressed HopA1-induced ETI also suppressed an ETI response induced by AvrRpm1 in Arabidopsis thaliana. A. thaliana plants expressing either HopAO1 or HopF2, two type III effectors that suppressed the HopA1induced HR, were reduced in the flagellin-induced PTI response as well as PTI induced by other PAMPs and allowed enhanced in planta growth of $P$. syringae. Collectively, our results suggest that the majority of DC3000 type III effectors can suppress plant immunity. Additionally, the construct pLN1965 will likely be a useful tool in determining whether other type III effectors or effectors from other types of pathogens can suppress either ETI, PTI, or both.

Pseudomonas syringae is a gram-negative bacterial plant pathogen that requires a type III protein secretion system (T3SS) and the type III effectors that it injects into plant cells to be pathogenic. The T3SS in P. syringae is encoded by hypersensitive response and pathogenicity (hrp) and hrp conserved $(h r c)$ genes in the Hrp pathogenicity island (Alfano et al. 2000; Collmer et al. 2000). The T3SS injects type III effectors into host cells in which they contribute to disease in susceptible plants, primarily by suppression of plant innate immu-

Ming Guo and Fang Tian contributed equally to this work.

Corresponding author: J. R. Alfano; E-mail: jalfano2@unl.edu

* The $e$-Xtra logo stands for "electronic extra" and indicates that Figures 4 and 5 appear in color online. nity (Abramovitch et al. 2006; Espinosa and Alfano 2004). In resistant plants however, type III effectors can be recognized by plant resistance $(\mathrm{R})$ proteins inducing effector-triggered immunity (ETI), which includes the elicitation of the hypersensitive response (HR), a programmed cell death in plants. ETI makes up one of the two branches of the innate immune system of plants (Jones and Dangl 2006).

The other branch of the plant innate immune system is activated by recognition of pathogen-associated molecular patterns (PAMPs) and is referred to as PAMP-triggered immunity (PTI) (Nurnberger et al. 2004; Zipfel 2008). PAMPs are present in pathogenic and nonpathogenic microorganisms and are also referred to as microbe-associated molecular patterns (MAMPs) (Ausubel 2005). One of the PAMPs whose role in inducing PTI is best understood is bacterial flagellin, which is recognized by the Arabidopsis thaliana receptor kinase FLS2 (Gomez-Gomez and Boller 2000; Zipfel et al. 2004). FLS2 also recognizes a conserved peptide of flagellin, flg22, that is often used in assays to induce outputs of PTI, including callose ( $\beta-1,3$ glucan) deposition in the plant cell wall (Gomez-Gomez et al. 1999).

In 1988, a paper reported a cosmid named pHIR11 that contained a cluster of hrp/hrc genes from $P$. syringae pv. syringae 61 that, when expressed in saprophytes such as $P$. fluorescens, conferred upon them the ability to elicit an HR in tobacco (Huang et al. 1988). This predated the discovery that hrp/hrc genes encoded a T3SS, but it proved to be a useful tool to explore the function of these genes in $P$. syringae. For example, pHIR11 was instrumental in identifying the first protein found to be secreted by the P. syringae T3SS (HrpZ1) (He et al. 1993). At that time, HrpZ1 was thought to be responsible for the HR elicited by $P$. syringae because it was encoded by pHIR11, it was a type III-secreted protein, and purified HrpZ1 infiltrated into tobacco leaves elicited an HR. However, it was subsequently determined that a nonpolar insertion in $h r p Z l$ in pHIR11 retained the ability to elicit an HR when expressed in P. fluorescens (Alfano et al. 1996). Thus, even though purified HrpZ1 elicited an HR, it was unlikely to be the elicitor of the bacterial-induced HR. This realization led to the discovery that HopA1 (formerly HrmA and HopPsyA) was the type III effector encoded by pHIR11 that was responsible for the pHIR11-induced HR and that HopA1 needed to be inside plant cells to elicit the HR (Alfano et al. 1997).

We have used pHIR11 as a tool to elucidate different components of the T3SS. For example, we used pHIR11 to help show that HopA1 required the ShcA type III chaperone to be secreted via the T3SS (van Dijk et al. 2002). Importantly, for the research we describe here, we previously used $P$. fluores- 
cens(pHIR11) in an assay in which we also expressed newly discovered type III effectors from $P$. syringae pv. tomato DC3000, to determine whether they could suppress the pHIR11-dependent HR. Remarkably, we found that seven of the 19 DC3000 type III effectors tested could fully or partially suppress the pHIR11-dependent HR (Jamir et al. 2004). pHIR11 has also been used to show that Xanthomonas campestris pv. vesicatoria type III effectors could also suppress HopA1-induced ETI (Fujikawa et al. 2006). Thus, pHIR11 has proved to be a simple and effective tool to increase our understanding of the T3SS in bacterial plant pathogens.

We modified pHIR11 by substituting hopAl with a kanamycin-resistance cassette, resulting in construct pLN18 (Jamir et al. 2004). This construct allowed us to perform bacterial mixing experiments to show that a type III effector could suppress ETI, even when delivered by a different bacterial strain from the one injecting the recognized type III effector (Jamir et al. 2004). Because P. fluorescens(pLN18) does not inject any type III effector but does contain PAMPs and induces PTI, this strain was used to show that a number of DC3000 type III effectors could suppress a PTI output (Oh and Collmer 2005).

Here, we test 35 DC3000 type III effectors for their ability to suppress pHIR11-dependent ETI and find that the majority are capable of ETI suppression. We also show that the well-

Table 1. DC3000 type III effectors tested for their ability to suppress a HopA1-dependent hypersensitive response (HR) in tobacco elicited by Pseudomonas fluorescens(pHIR11)

\begin{tabular}{|c|c|c|}
\hline Type III effectors & Plasmid & Suppression class ${ }^{\mathbf{a}}$ \\
\hline AvrE & pLN2423 & II \\
\hline AvrPto & pLN1327 & II \\
\hline AvrPtoB & pLN347 & I \\
\hline HopA1 & pLN1326 & II \\
\hline HopB1 & pLN271 & IV \\
\hline HopC1 & pLN50 & III \\
\hline HopD1 & pLN167 & I \\
\hline HopE1 & pLN162 & I \\
\hline HopF2 & pLN1420 & I \\
\hline HopG1 & pLN460 & II \\
\hline НорН1 & pLN150 & II \\
\hline HopI1 & & Not tested \\
\hline HopK1 & pCPP5100 & I \\
\hline HopM1 & pLN1156 & II \\
\hline HopN1 & pLN1324 & II \\
\hline HopO1-1 & pLN1622 & II \\
\hline HopO1-2 & pLN1623 & II \\
\hline HopQ1-1 & pLN518 & III \\
\hline HopR1 & pLN1154 & II \\
\hline HopS2 & pLN1624 & I \\
\hline НорТ1-1 & pLN256 & III \\
\hline НорТ1-2 & pLN567 & III \\
\hline HopU1 & pLN223 & II \\
\hline HopV1 & pLN517 & II \\
\hline HopX1 & pCРP5068 & I \\
\hline HopY1 & pLN1528 & II \\
\hline HopAA1-1 & pLN1326 & III \\
\hline HopAA1-2 & pLN1419 & II \\
\hline HopAD1 & pLN165 & III \\
\hline HopAF1 & pLN164 & II \\
\hline HopAI1 & pLN1011 & IV \\
\hline HopAM1 & pCРP5063 & I \\
\hline HopAN1 & pLN1329 & II \\
\hline HopAO1 & pLN130 & II \\
\hline HopAQ1 & pLN1331 & II \\
\hline HopAS1' & pLN1328 & IV \\
\hline
\end{tabular}

${ }^{\text {a }}$ Class I suppressors are type III effectors that suppressed the HopA1dependent HR at $1 \times 10^{8}$ cells $/ \mathrm{ml}$; class II completely suppressed the HR at $2 \times 10^{7}$ cells $/ \mathrm{ml}$; class III suppressors are type III effectors that were variable in their ability to suppress the HopA1-dependent HR at $2 \times 10^{7}$ cells $/ \mathrm{ml}$; and class IV contains type III effectors that were unable to suppress the HR at $2 \times 10^{7}$ cells $/ \mathrm{ml}$. characterized type III effectors AvrRpm1 and AvrRpt2 are also capable of suppressing pHIR11-dependent ETI. We made a derivative of pHIR11 named pLN1965 that substituted hopAl with a spectinomycin-resistance cassette. $P$. fluorescens (pLN1965) separately expressing different DC3000 type III effectors also suppressed the AvrRpm1-dependent ETI as well as PTI in Arabidopsis thaliana. Taken together, our data indicate that the vast majority of the DC3000 type III effectors can suppress ETI and that many of them can also suppress PTI. This suggests that either common targets for type III effectors are utilized in pathways needed for both ETI and PTI, that many type III effectors have multiple activities, or both. Additionally, construct pLN1965 will likely be useful for testing whether other type III effectors and effectors from other types of plant pathogens can suppress plant immunity.

\section{RESULTS}

\section{Screening the DC3000 type III effector inventory for suppressors of the HopA1 effector-triggered HR.}

The cosmid pHIR11 encodes a functional T3SS and one type III effector HopA1 (Alfano and Collmer 1997; Lindeberg et al. 2005; van Dijk et al. 1999). We previously used this cosmid to screen DC3000 type III effectors for their ability to suppress the HopA1-induced HR when expressed in P. fluorescens (Jamir et al. 2004). Nineteen type III effectors were screened, and five, AvrPtoB (HopAB2), HopE1, HopF2, HopX1 (AvrPphE), and HopAM1 (AvrPpiB1), were capable of completely suppressing the HopA1-induced HR, while two others, HopD1 and HopK1, had an intermediate ability to suppress this HR (Jamir et al. 2004).

If the DC3000 type III effector inventory is limited to type III effectors that have been confirmed or to those for which there exists experimental evidence supporting that they are type III effectors, there are 36 type III effectors present in DC3000 (Lindeberg et al. 2005, 2006). We tested the remaining 29 DC3000 type III effectors in the P. fluorescens(pHIR11) assay with the exception of HopI1, due to difficulties in the isolation of its gene. Type III effector genes were cloned into pLN615 and were transformed into P. fluorescens(pHIR11). Each strain expressing individual type III effectors was infiltrated into tobacco leaves at a cell density of $1 \times 10^{8}$ cells $/ \mathrm{ml}$ and was examined for its ability to suppress the HopA1-dependent HR by comparing each test strain with a control strain on the same leaf. Surprising, only one additional type III effector, HopS2, was capable of completely suppressing the HopA1dependent HR at this cell density (Fig. 1). The suppression activity of HopS2 required the presence of the HopS2 cognate type III chaperone, which has been shown to be required for HopS2 to be secreted via the T3SS (Guo et al. 2005).

Based on the number of type III effectors that possessed suppressor activity in our earlier study (Jamir et al. 2004), we expected that many more of the remaining DC3000 type III effectors would be capable of suppressing the HopA1-dependent HR. We speculated that our assays may have failed to detect additional DC3000 type III effectors capable of suppressing the HR because the cell densities used far exceeded the threshold cell density needed for HR elicitation and this may have left unidentified type III effectors that possessed less-substantial suppressor activity. P. fluorescens(pHIR11) maintains its ability to elicit a consistent confluent HR at a cell density of $2 \times 10^{7}$ cells $/ \mathrm{ml}$ and, therefore, we retested all of the type III effectors at this cell density. When DC3000 type III effectors were retested in the $P$. fluorescens(pHIR11) system at the lower cell density, the vast majority of them were able to suppress the HopA1-dependent HR (Table 1). To distinguish between the different levels of HR suppression activity displayed 
by different type III effectors, we separated them into different suppressor classes: Class I suppressors were type III effectors that suppressed the HopA1-dependent HR at $1 \times 10^{8}$ cells $/ \mathrm{ml}$, class II completely suppressed the $\mathrm{HR}$ at $2 \times 10^{7}$ cells $/ \mathrm{ml}$, class III contained type III effectors that were variable in their ability to suppress the HopA1-dependent $\mathrm{HR}$ at $2 \times 10^{7}$ cells $/ \mathrm{ml}$, and class IV contained type III effectors that were unable to suppress the HR at $2 \times 10^{7}$ cells $/ \mathrm{ml}$. Class I contained eight type III effectors, class II contained 18 type III effectors, class III contained six type III effectors, and class IV contained three type III effectors.

Two well-studied type III effectors, AvrRpm1 and AvrRpt2, can also suppress the HR induced by HopA1.

Much is known about the activities and targets for the type III effectors AvrRpm1 and AvrRpt2 (Axtell and Staskawicz. 2003; Kim et al. 2005; Mackey et al. 2002, 2003). We tested whether these type III effectors were capable of suppressing the HR elicited by P. fluorescens(pHIR11) in experiments similar to the ones described above. The control strain elicited an $\mathrm{HR}$ at densities of $1 \times 10^{8}$ and $2 \times 10^{7}$ cells $/ \mathrm{ml}$, whereas strains harboring pVSP61::avrRpml and pLN1906, which expressed AvrRpm1 and AvrRpt2, respectively, did not elicit an HR at these cell densities (Fig. 2). Thus, both AvrRpm1 and AvrRpt2 strongly suppressed the HopA1-dependent HR in tobacco and, by the classification used in Table 1, would both be considered class I suppressors. AvrRpm1 and AvrRpt2 have been reported to suppress PTI (Kim et al. 2005). Our results indicate that AvrRpm1 and AvrRpt 2 can also suppress a HopA1-dependent ETI response, consistent with earlier reports indicating that these type III effectors could interfere with AvrRpm1-dependent and AvrRpt2-dependent ETI responses (Reuber and Ausubel 1996; Ritter and Dangl 1996).

\section{Testing type III effector suppression of other ETI responses} using a modified pHIR11 system.

In our earlier report, we modified pHIR11 by replacing hopAl with a kanamycin-resistance cassette resulting in pLN18, which encodes a functional T3SS and allows for the injection of other effectors into plant cells when expressed in $P$. fluorescens. However, P. fluorescens(pLN18) is limited because it uses kanamycin resistance to maintain pLN18. This is significant because $P$. fluorescens 55 is resistant to most of the other antibiotics commonly used to select for broad-host-range plasmids. To address this issue, we made a derivative of pLN18 in which the kanamycin-resistance cassette is replaced with a spectinomycin-resistance cassette resulting in construct pLN1965. P. fluorescens(pLN1965) allowed us to test whether other ETI responses were also suppressed by the type III effector that suppressed the HopA1-dependent HR. We introduced
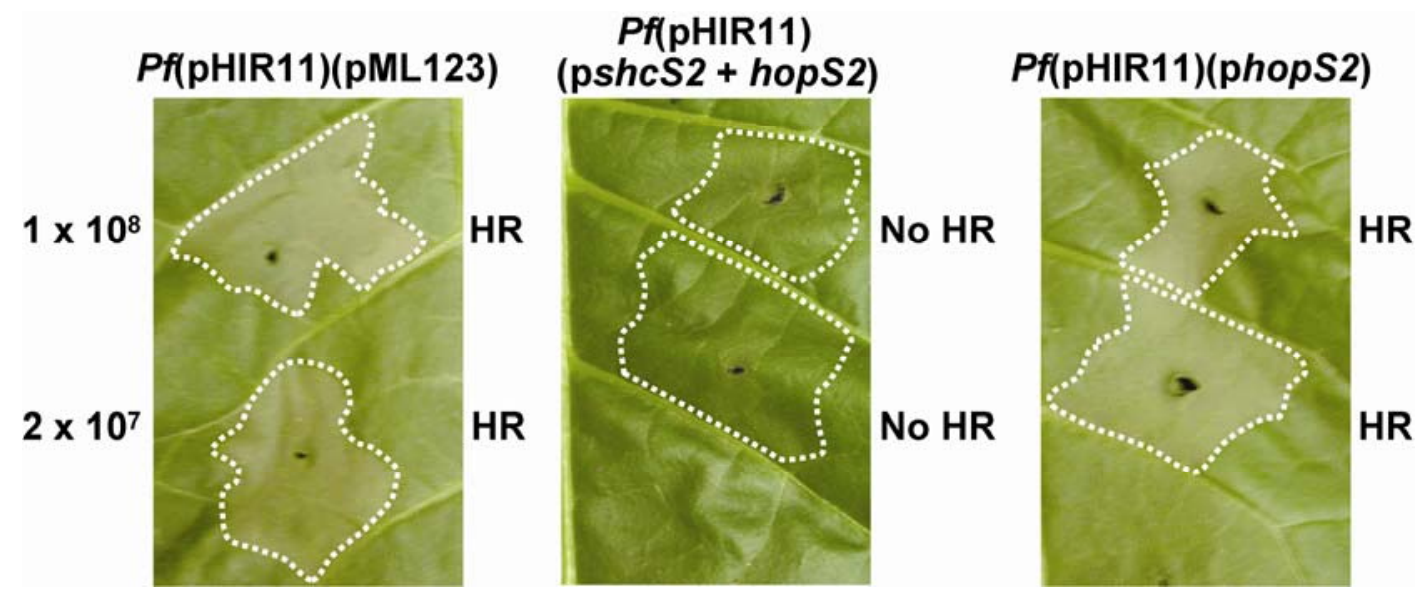

Fig. 1. The Pseudomonas syringae pv. tomato DC3000 type III effector HopS2 can suppress the HopA1-dependent hypersensitive response (HR) elicited by P. fluorescens(pHIR11). P. fluorescens(pHIR11) strains carrying a control vector, pLN1624 (pshcS2 + hopS2) containing hopS2 with its type III chaperone gene shcS2, or pLN452 (phopS2) expressing hopS2 alone were infiltrated into Nicotiana tabacum cv. Xanthi leaves at a cell density of $1 \times 10^{8}$ or $2 \times 10^{7}$ cells $/ \mathrm{ml}$. The leaves were evaluated for production of a HR and were photographed after $48 \mathrm{~h}$. The ability of HopS2 to suppress the HopA1-dependent HR was dependent on the presence of its cognate type III chaperone ShcS2. This experiment was repeated 10 times with similar results.
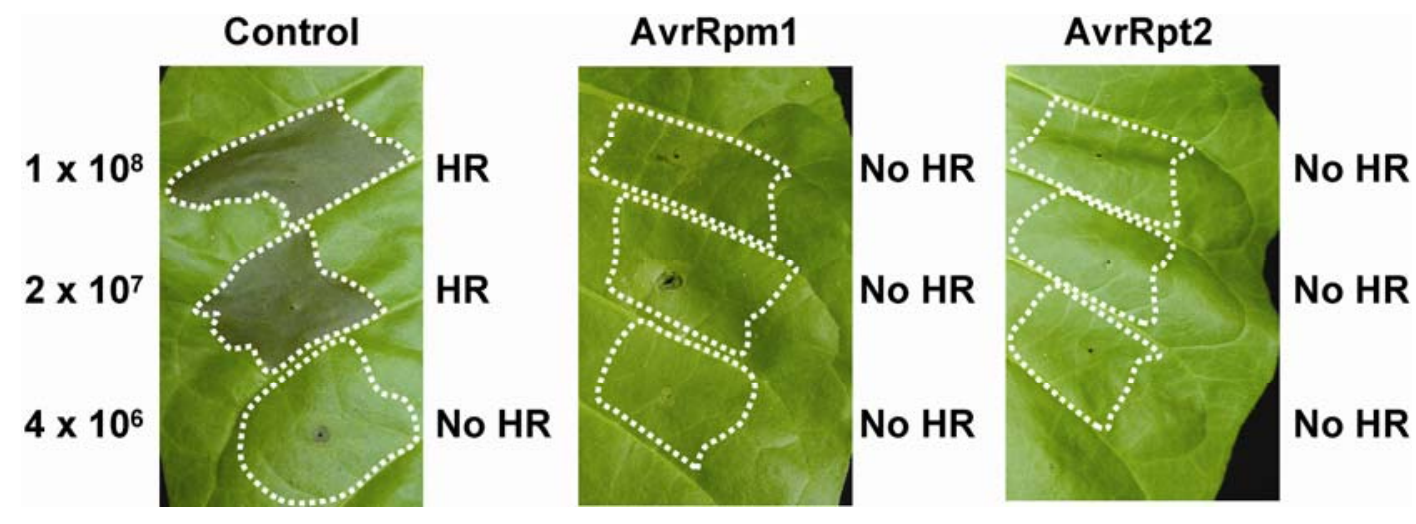

Fig. 2. Pseudomonas syringae type III effectors AvrRpm1 and AvrRpt2 can suppress the HopA1-dependent hypersensitive response (HR) in tobacco. P. fluorescens(pHIR11) strains carrying constructs pVSP61::avrRpm1 (pavrRpm1), pLN1906 (pavrRpt2), or a vector control were infiltrated into Nicotiana tabacum cv. Xanthi leaves. P. fluorescens(pHIR11) carrying a vector control elicits a HR at the rate of $1 \times 10^{8}$ and $2 \times 10^{7}$ cells/ml, whereas the HR is suppressed in the . fluorescens(pHIR11) strains expressing avrRpm1 or avrRpt2, indicating that AvrRpm1 and AvrRpt2 can suppress the HopA1-dependent HR. Tobacco leaves were evaluated for the development of the HR and were photographed $48 \mathrm{~h}$ after infiltration. 
avrRpml on a broad-host-range plasmid into $P$. fluorescens (pLN1965), also carrying compatible plasmids that encoded either HopE1, HopF2, AvrPtoB, HopAM1, or HopX1 and infiltrated each of these strains into A. thaliana Col-0. AvrRpm1 is recognized by $\mathrm{R}$ protein RPM1 present in this accession of $A$. thaliana, inducing ETI (Grant et al. 1995). All of these type III effectors were capable of suppressing the AvrRpm1-dependent HR (Fig. 3A). Callose deposition in the plant cell wall is another output of ETI. Using the same strains, we determined that each of these type III effectors was capable of reducing the amount of AvrRpm1-dependent callose deposition (Fig. 3B and C), indicating that these type III effectors can suppress multiple outputs of ETI.

Class I HR suppressors can also inhibit callose deposition induced by $\boldsymbol{P}$. fluorescens PAMPs.

P. fluorescens(pLN1965) does not elicit an HR because it does not inject any type III effectors. However, it does contain flagellin and likely other PAMPs that are recognized by plants that lead to PTI. We found that when P. fluorescens(pLN1965) was infiltrated into $A$. thaliana Col-0 leaves, it induces callose deposition (Fig. 4), which is likely due to the recognition of $P$. fluorescens PAMPs. We infiltrated P. fluorescens(pLN1965) expressing either AvrPtoB, HopE1, HopF2, HopX1, or HopAM1 into A. thaliana Col-0 leaves, to test whether they were able to suppress callose deposition induced by $P$. fluorescens(pLN1965). Indeed, in each case, the callose deposition was reduced compared with that in a control strain (Fig. 4). Taken together, the ability of type III effectors to suppress callose deposition induced by both AvrRpm1 and P. fluorescens (pLN1965) suggests that either ETI and PTI responses overlap in their signaling pathways or that type III effectors can separately target unique components in each pathway, or both.

\section{HopAO1 and HopF2 suppress flg22-induced} innate immunity.

To further study the suppression of innate immunity by type III effectors, we chose to make transgenic A. thaliana Col-0
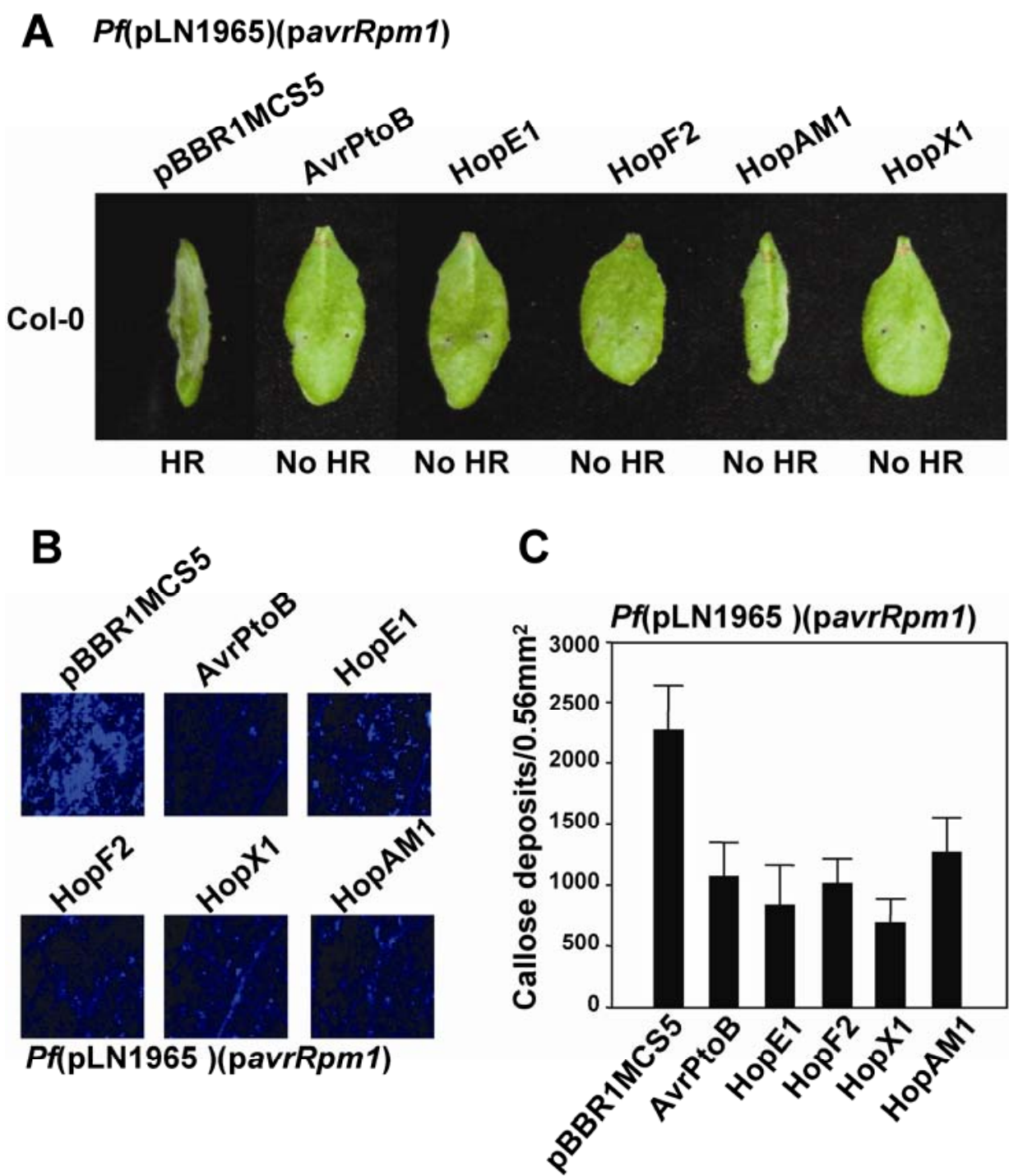

Fig. 3. Modification of the Pseudomonas fluorescens(pHIR11) system shows that a subset of type III effectors that are class I suppressors can also suppress the AvrRpm1-dependent effector-triggered immunity. A, Arabidopsis thaliana ecotype Col-0 leaves were infiltrated with P. fluorescens(pLN1965)(pavrRpm1) strains carrying an empty vector (pBBR1MCS5) or constructs that expressed different type III effectors known to suppress the HopA1-dependent hypersensitive response (HR). In each case, the type III effector was also capable of suppressing the AvrRpm1-dependent HR. B, A. thaliana ecotype Col-0 leaves were infiltrated with P. fluorescens(pLN1965)(pavrRpm1) strains carrying an empty vector (pBBR1MCS5) or constructs that expressed different type III effectors known to suppress the HopA1-dependent HR. Callose deposition induced by AvrRpm1 was suppressed in strains that expressed a type III effector known to suppress the HopA1-dependent HR. Leaves were microscopically viewed for evidence of callose deposition $16 \mathrm{~h}$ after infiltration.C, Callose deposits shown in B were quantified, and the average of 20 views of fields from five leaves and standard errors are shown. 
plants that express either the class I suppressor HopF2 or the class II suppressor HopAO1. We have previously shown that HopAO1 (formally HopPtoD2) and HopF2 were capable of suppressing an HR response induced by an avirulent $P$. syringae strain or HopA1 (Espinosa et al. 2003; Jamir et al. 2004). We made several independent transgenic $A$. thaliana Col-0 lines that express HopAO1 or HopF2 fused to the hemagglutinin (HA) epitope under control of the constitutive Cauliflower mosaic virus $35 \mathrm{~S}$ promoter. We confirmed that these lines expressed HopAO1-HA or HopF2-HA (Fig. 5A). When a conserved 22-amino acid peptide (flg22) from flagellin is infiltrated into A. thaliana, it induces PTI responses, which include callose deposition, alkalization, and an oxidative burst in a manner dependent on the FLS2 receptor kinase (Felix et al. 1999; Gomez-Gomez and Boller 2000; Gomez-Gomez et al. 1999). When $1 \mu \mathrm{M}$ flg 22 was infiltrated into transgenic plants expressing HopAO1-HA or HopF2-HA, they showed significantly reduced callose deposition compared with wild-type $A$. thaliana Col-0 plants (Fig. 5A and B). An inactive flg $22_{A t}$ peptide derived from Agrobacterium flagellin was used as a control in these experiments, since this peptide is known not to induce high levels of callose deposition. Thus, both HopAO1 and HopF2 exhibited the ability to suppress flg22-induced callose deposition in A. thaliana.

Another way to test whether plants expressing HopAO1-HA and HopF2-HA were capable of suppressing PTI-dependent callose deposition is to infiltrate a $P$. syringae type III-defective mutant (Hauck et al. 2003). Since a type III-defective mutant is unable to inject any type III effectors, any PAMP recognized by the plant results in PTI. We infiltrated a $P$. syringae pv. tomato DC3000 hrcC mutant defective in type III secretion into transgenic plants expressing HopAO1-HA or HopF2-HA and examined callose deposition $16 \mathrm{~h}$ postinfiltration. The numbers of callose deposits were significantly reduced in the HopAO1-HA or HopF2-HA transgenic plants compared with wild-type plants (Fig. 5C). This result suggests that HopAO1 and HopF2 can suppress PAMP-induced callose deposition and is consistent with their ability to suppress flg22-induced PTI.
We determined how much of the callose deposition induced by the DC3000 hrcC mutant was due to recognition of flagellin by constructing a DC3000 hrcC fliR double mutant. The $f l i R$ gene encodes a protein in the flagellar basal body that is required for flagellar biogenesis (Fan et al. 1997; Kubori et al. 1997). We infiltrated the DC3000 hrcC fliR double mutant into wild-type $A$. thaliana and found that it induced less than half the number of callose foci than did the DC3000 hrcC single mutant (Fig. 5C), suggesting that flagellin is a major PAMP in $P$. syringae-plant interactions. We also infiltrated the DC3000 $h r c C$ fliR mutant into $A$. thaliana Col-0 plants expressing either HopF2-HA or HopAO1-HA and found the residual callose deposition induced by the $h r c C$ fliR mutant was suppressed in these plants (Fig. 5C), indicating that these type III effectors can suppress PTI induced by PAMPs other than flagellin.

\section{DC3000 and a DC3000 type III-defective mutant grows to higher levels in A. thaliana plants expressing HopAO1-HA or HopF2-HA.}

If plants expressing HopAO1-HA or HopF2-HA have a reduced PTI response, we thought they may be less able to defend themselves against $P$. syringae. To test this, we sprayinoculated DC3000 or the DC3000 hrcC mutant into wild type and A. thaliana plants expressing HopAO1-HA or HopF2-HA and determined how well each strain grew in these plants. DC3000 grew to higher levels in plants expressing either HopAO1-HA or HopF2-HA (Fig. 6A). Pretreatment with flg22 slightly reduced DC3000 growth in all plant lines when compared with the corresponding untreated plants (Fig. 6B). However, the expression of HopAO1-HA or HopF2-HA allowed increased DC3000 growth with or without flg22 pretreatment, suggesting that the PTI response is not completely suppressed by DC3000 type III effectors. Additionally, growth of DC3000 in type III effector-expressing plants pretreated with flg22 was reduced compared with untreated type III effector-expressing plants, which suggests that the PTI response was not completely suppressed by the in planta overexpression of these type III effectors.
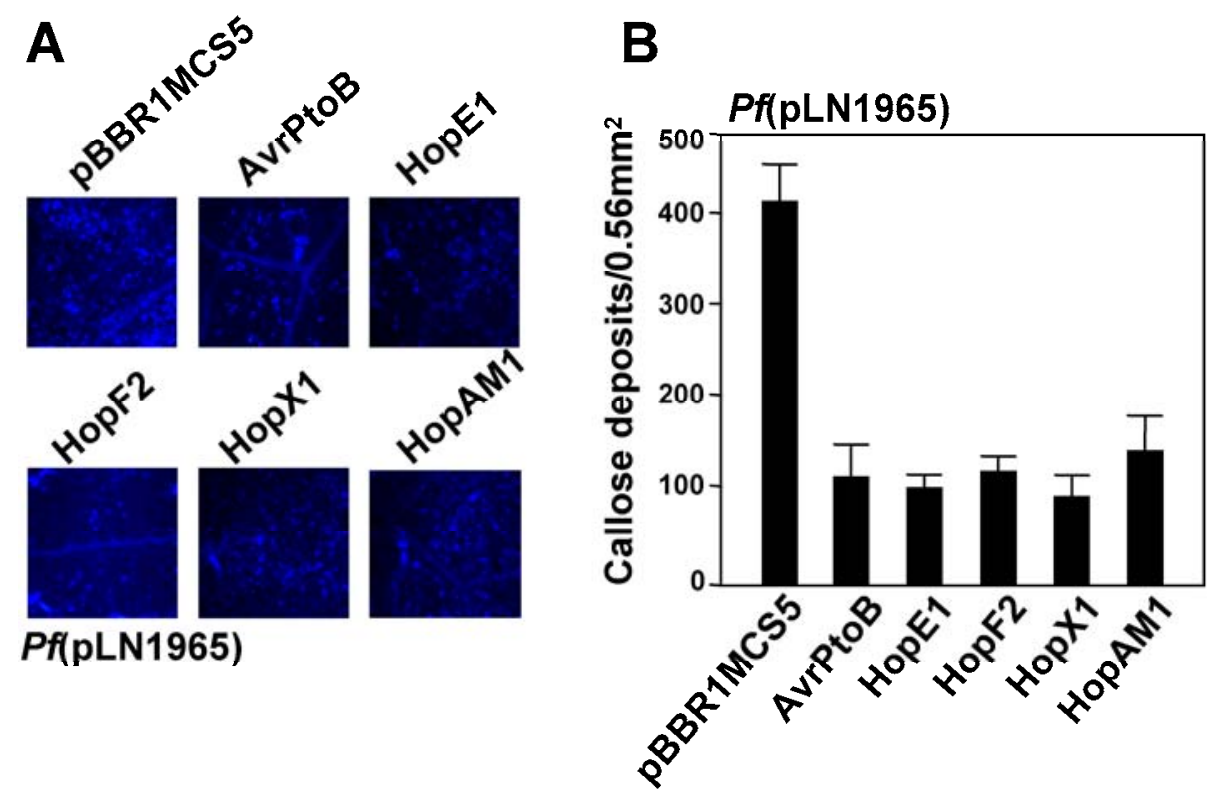

Fig. 4. Type III effectors belonging to the class I suppressor group can suppress callose deposition induced by pathogen-associated molecular pattern (PAMP)-triggered immunity. A, Arabidopsis thaliana ecotype Col-0 leaves were infiltrated with Pseudomonas fluorescens(pLN1965) strains carrying an empty vector (pBBR1MCS5) or constructs that expressed different type III effectors known to suppress the HopA1-dependent hypersensitive response. These type III effectors can suppress callose deposition triggered by PAMPs presented by P. fluorescens(pLN1965). Leaves were microscopically viewed for evidence of callose deposition $16 \mathrm{~h}$ after infiltration. B, Callose deposits shown in A were quantified, and the average of 20 views of fields from five leaves is shown. Each experiment was repeated three times with similar results, and the standard errors are indicated in the bar graphs. 


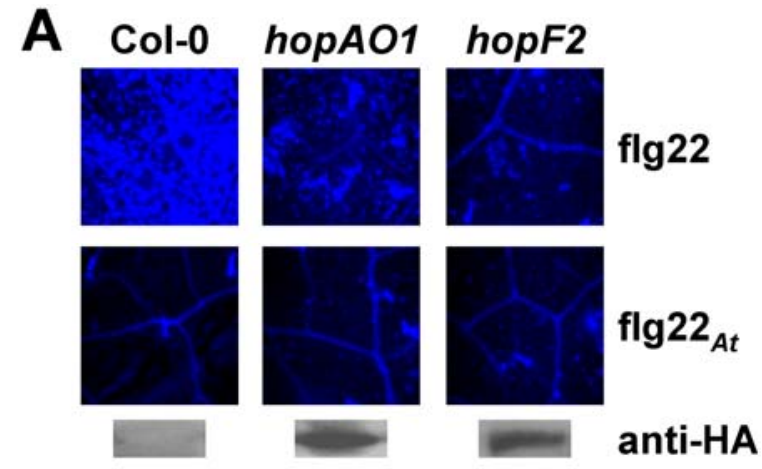

B
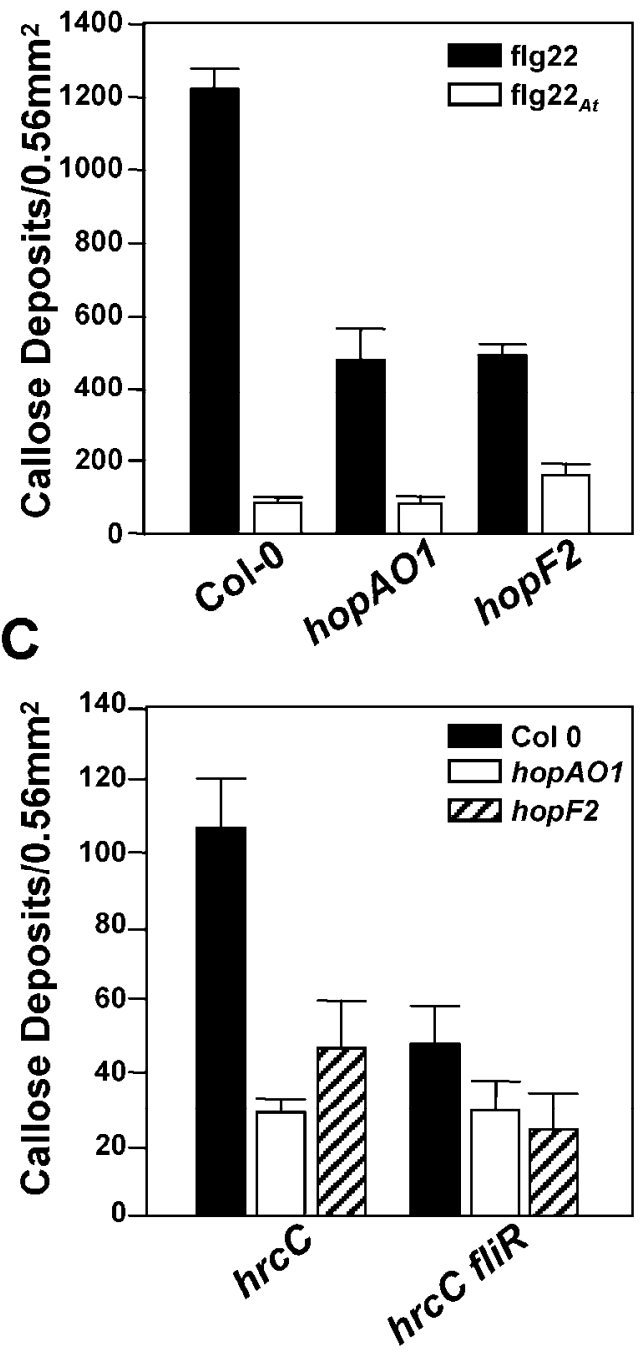

Fig. 5. Transgenic Arabidopsis thaliana plants expressing the HopAO1 or HopF2 type III effectors were reduced in pathogen-associated molecular pattern-triggered callose deposition. A, Callose deposition was visualized in wild-type $A$. thaliana Col-0 plants or in plants expressing HopAO1 hemagglutinin (HA) or HopF2-HA $16 \mathrm{~h}$ after treatment with flg22 or flg2 $22_{A t}$, an inactive peptide from Agrobacterium flagellin. Immunoblots were carried out using anti-HA antibody on leaf tissue samples from plants used in the experiment, to confirm that HopAO1-HA and HopF2-HA were produced. B, Callose deposition in plants depicted in A was quantified by counting the number of callose foci per field of view. C, Callose deposition induced by a DC3000 hrcC mutant (defective in the ype III protein secretion system) or a DC3000 hrcC fliR (defective in flagellar biogensis) double mutant was quantified as noted in $\mathrm{B}$. The numbers of callose foci in B and C are averages of 20 fields of view (four views per leaf samples) and standard errors are shown. All experiments were repeated three times with similar results.
The DC3000 hrcC mutant normally has restricted growth in planta, likely due to the induction of PTI and the inability of this mutant to suppress it by injecting type III effectors. Therefore, in planta growth assays using the $\mathrm{hrcC}$ mutant is another measure of PTI suppression (Hauck et al. 2003). In our experiments, the $h r c C$ mutant accumulated to approximately 300-fold higher levels in A. thaliana plants expressing either HopAO1-HA or HopF2-HA compared with wild-type $A$. thaliana Col-0 plants (Fig. 6C). Taken together, these results suggest that both HopAO1 and HopF2 suppress PTI and ETI responses and this suppression allows the pathogen to grow better in plants.

\section{DISCUSSION}

In this report, we tested 35 DC3000 type III effectors for their ability to suppress the HopA1-dependent HR using $P$. fluorescens carrying cosmid pHIR11, which encodes a functional T3SS and one type III effector HopA1. The pHIR11 system was first used to assay for type III effectors that suppress the HR by Jamir and associates (2004). This earlier report tested 19 DC3000 type III effectors and identified seven that could suppress the HopA1-dependent HR. Here, we have extended this assay to include the complete DC3000 inventory of confirmed and likely type III effectors (Lindeberg et al. 2006), with the only exception being HopI1.

Based on our earlier results, we were expecting many more DC3000 type III effectors to completely suppress the HopA1dependent HR when $P$. fluorescens (pHIR11) was infiltrated into tobacco at a cell density of $1 \times 10^{8}$ cells $/ \mathrm{ml}$. However, we identified only one additional DC3000 type III effector capable of HR suppression at this titer. This prompted us to infiltrate plants with bacteria at a cell density closer to the threshold cell density needed for production of a macroscopic HR and, when we did so, the majority of the DC3000 type III effectors possessed substantial HR suppression activity (Table 1). Each DC3000 type III effector was assigned to one of four different classes of HR suppressor, and there were only a few cases in which we were unable to detect any suppression of the HopA1-dependent HR.

The newly identified DC3000 type III effector as a class I suppressor was HopS2. Other than some similarity in its N-terminal secretion signal with HopS1', HopS2 has no obvious similarity with any proteins in the databases (Guo et al. 2005). We showed earlier that hopS2 was expressed in conditions that induce expression of the T3SS and that HopS2 is injected into plant cells in a manner dependent on its type III chaperone ShcS2 (Guo et al. 2005). Based on a limited study, hopS2 appeared to be well distributed in different $P$. syringae pathovars (Guo et al. 2005). The fact that this type III effector possesses particularly strong HR suppressor activity makes it an attractive type III effector to study further, to identify its plant targets. Our HR suppressor screen also included the well-characterized type III effectors AvrRpm1 and AvrRpt2 from other $P$. syringae strains, which were found also to be class I HR suppressors (Fig. 2). Both of these type III effectors are known to target RIN4 (Axtell and Staskawicz 2003; Mackey et al. 2003). RIN4 associates with RPM1 and RPS2, the R proteins that recognize AvrRpm1 and AvrRpt2, respectively, and modification of RIN4 appears to lead to induction of ETI. It would be of interest to know if the HopA1-dependent ETI response is also dependent on RIN4. Whatever the case, because of their similarly strong ability to suppress HopA1-induced ETI, it is possible that the type III effectors that make-up class I suppressors target related innate immunity components.

We modified cosmid pHIR11 to allow us to test whether a subset of the class I HR suppressors could also suppress the 
HR induced by a different type III effector. This pHIR11 derivative, pLN1965, still encodes a functional T3SS but lacks hopA1. Using P. fluorescens (pLN1965), we showed that the type III effectors HopE1, HopF2, AvrPtoB, HopAM1, and HopX1, which were class I suppressors, all were capable of suppressing the AvrRpm1-dependent HR and callose deposition in A. thaliana Col-0 (Fig. 3). Because $P$. fluorescens(pLN1965) does not inject any type III effectors that induce ETI but does induce PTI, this system also allowed us to demonstrate that these five type III effectors also suppressed PTI-induced callose deposition (Fig. 4). In the majority of published reports, $P$. syringae type III effectors have been shown to suppress PTI or ETI, but both types of immunity generally are not tested. The most notable exceptions to this are the type III effectors AvrPtoB and HopAO1, which have been shown to suppress both ETI and PTI (Abramovitch and Martin 2005; Bretz et al. 2003; de Torres et al. 2006; Espinosa et al. 2003; Rosebrock et al. 2007; Underwood et al. 2007). The results from this study suggest that many $P$. syringae type III effectors likely suppress both ETI and PTI, possibly because type III effectors have multiple plant targets or their plant targets have roles in either one or both ETI and PTI.

We envision that $P$. fluorescens(pLN1965) will be useful for researchers studying other type III effectors. For example, they could use this system to screen whether the type III effectors they are interested in induce ETI or suppress innate immunity. Moreover, the system could be adapted for the identification of effectors from other bacterial, oomycete, fungal, or viral pathogens. Recently oomycete effector genes were identified by fusing candidate effector genes to nucleotide sequences corresponding to the N-terminal type III secretion signal of different $P$. syringae type III effectors (Rentel et al. 2008; Sohn et al. 2007). Expressing these fusion proteins in $P$. syringae allowed them to be injected into plant cells via the T3SS, facilitating the discovery of their in planta effects. However, studying these heterologous effectors in the wild-type $P$. syringae background may mask some of their effects in plant cells, due to the injection of many $P$. syringae type III effectors. We suggest that performing analogous experiments using $P$. fluorescens (pLN1965) may provide clearer plant phenotypes because this system does not inject any other type III effectors that could potentially mask interesting phenotypes. In addition, because this strain does not grow well in plant tissue determining whether a test effector contributes to in planta growth may be made more clear.

To investigate two of the type III effectors in planta phenotypes in more detail, we made transgenic A. thaliana plants that constitutively expressed a class I suppressor, HopF2, and a class II suppressor, HopAO1. We found that transgenic expression of both of these type III effectors suppressed flg22induced PTI (Fig. 5). HopAO1 is a protein tyrosine phosphatase that has been previously shown to suppress a nonhost HR and other ETI responses (Bretz et al. 2003; Espinosa et al. 2003), and more recently, it has been shown to suppress PTI responses, using transgenic $A$. thaliana plants expressing HopAO1 (Underwood et al. 2007). Our experiments reported here with $A$. thaliana HopOA1-expressing plants essentially confirm that these plants are suppressed in their PTI responses. In our experiments, flg22 pretreatment still reduced the ability of DC3000 to multiply in HopAO1-expressing plants compared with untreated plants. Thus, HopAO1 did not completely suppress the PTI response in these plants, as it did in the earlier study.

The PTI response in A. thaliana plants expressing HopF2 was also suppressed based on the suppression of flg22-induced callose deposition, and the increased growth of the DC3000 type III-defective $h r c C$ mutant. Other reports have suggested that HopF2 was capable of suppressing both ETI in tobacco
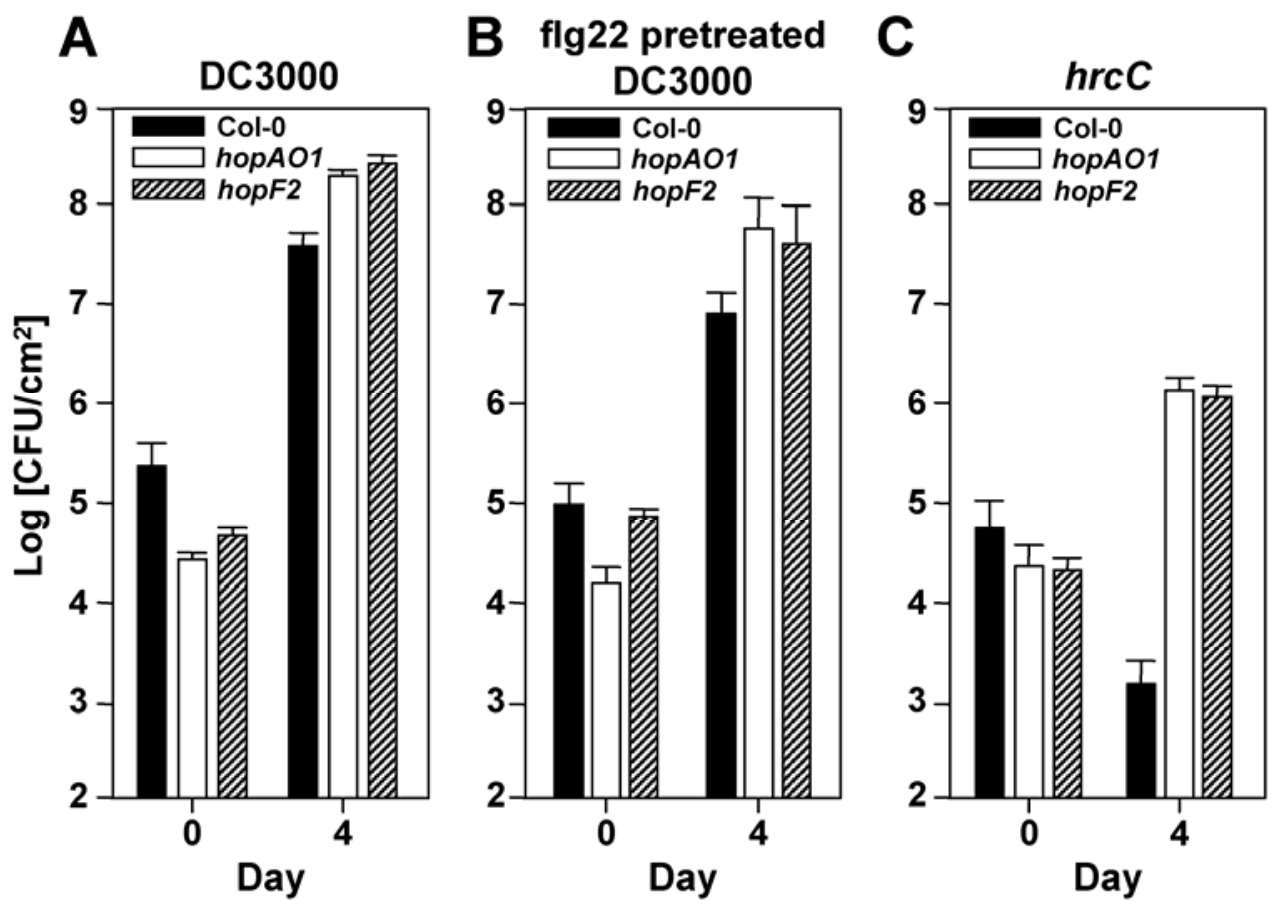

Fig. 6. Transgenic Arabidopsis thaliana plants expressing HopAO1 or HopF2 are more susceptible to Pseudomonas syringae and a type III-defective mutant than is wild-type Arabidopsis. A, A. thaliana Col-0 plants were spray-inoculated with P. syringae pv. tomato DC3000. DC3000 was able to grow to higher levels in plants expressing HopAO1 or HopF2 than in A. thaliana Col-0. B, A. thaliana Col-0 plants were pretreated with $1 \mu \mathrm{M}$ flg22, and after $16 \mathrm{~h}$, were spray-inoculated with DC3000. Overall, the pretreatment with flg22 reduced bacterial growth comp plants ared with non-pretreated plants in A. DC3000 grew to higher levels on plants expressing HopAO1 and HopF2 than it did on A. thaliana Col-0. C, A. thaliana were spray-inoculated with a DC3000 hrcC. The growth of the DC3000 hrcC mutant was enhanced in transgenic plants expressing HopAO1 or HopF2 as compared with wild-type Col-0. In all experiments, plants were inoculated at a cell density of $2 \times 10^{8}$ cells $/ \mathrm{ml}$, and bacteria were enumerated at days 0 and 4 . 
and PTI in Nicotiana benthamiana when delivered by bacteria (Jamir et al. 2004; Oh and Collmer 2005). Another report indicated that HopF2 and a number of other P. syringae type III effectors were capable of suppressing flagellin-induced gene expression in A. thaliana protoplasts (Li et al. 2005) consistent with HopF2 suppressing PTI. The enzymatic activity of HopF2 and its plant targets are currently unknown. However, its molecular structure has been determined, and one portion of it shared limited structural similarity with ADP-ribosyltransferases, but this activity could not be demonstrated (Singer et al. 2004). The results described here further establish that HopF2 can suppress both ETI and PTI.

A DC3000 hrcC fliR double mutant was capable of inducing callose deposition, although it was greatly reduced, indicating that flagellin is a primary PAMP in A. thaliana Col-0. Transgenic $A$. thaliana plants expressing HopAO1 or HopF2 were suppressed in their callose deposition in response to the DC3000 hrcC fliR double mutant, indicating that these type III effectors suppressed PTI responses induced by PAMPs other than flagellin. This is consistent with the induction of PTI in A. thaliana plants defective in FLS2, the receptor kinase that recognizes flagellin, which suggests that additional bacterial PAMPs are recognized by A. thaliana Col-0 (Zipfel et al. 2004). We now know that one of these additional bacterial PAMPs is the translation elongation factor EF-Tu (Zipfel et al. 2006), but likely other bacterial PAMPs and PAMP receptors await discovery.
Evolutionary models suggest that bacterial pathogens first acquired type III effectors that suppressed only PTI (Chisholm et al. 2006; Espinosa and Alfano 2004). The rationale behind this is that the existence of PTI likely predated ETI and that PTI probably was the primary selection for pathogens to initially acquire a T3SS and a minimal set of type III effectors. The most logical place to look for genes encoding type III effectors that target PTI but not ETI is in the conserved effector locus (CEL) within the Hrp pathogenicity island (Alfano et al. 2000) because these type III effectors genes are conserved in all $P$. syringae strains tested and because acquiring an apparatus without type III effector genes would serve little benefit to the pathogen. Interestingly, two conserved type III effector genes within the CEL are avrE and hopM1 and both are class II suppressors in HopA1-induced HR suppression assays, indicating that both were capable of suppressing ETI. These results suggest that these type III effectors either act on host targets needed for both PTI and ETI, or they contain multiple activities, or both. Moreover, these results imply that the archetypal type III effectors may have also had the ability to suppress both PTI and ETI, which suggests that HopM1 and AvrE1 target components used in both ETI and PTI.

Collectively our results indicate that the lion's share of $P$. syringae type III effectors suppress plant innate immunity. However, they also illustrate the need for assays that report more specifically the responses affected in the host as well as the

Table 2. Strains and plasmids used in this study

\begin{tabular}{|c|c|c|}
\hline Strain or plasmid & Characteristics $^{\mathrm{a}}$ & Reference or source \\
\hline \multicolumn{3}{|l|}{ E. coli } \\
\hline DH5 $\alpha$ & supE44 AlacU169( ф80lacZ4M15) hsdR17 recA1 endA1 gyrA96 thi-1 relA1, $\mathrm{Nal}^{\mathrm{r}}$ & $\begin{array}{l}\text { Hanahan 1983; Life Technologies, } \\
\text { Gaithersburg, MD, U.S.A. }\end{array}$ \\
\hline DB3.1 & $\begin{array}{l}F^{-} \text {gyrA462 endA1 } \Delta(\text { srl-recA }) \text { mcrB mrr hsdS2O }\left(r_{\mathrm{B}}{ }^{-}, m_{\mathrm{B}}{ }^{-}\right) \text {supE44 ara-14 galK2 } \\
\text { lacY1 proA2 rpsL2O }\left(\mathrm{Sm}^{\mathrm{r}}\right) \text { xyl-5 } \lambda^{-} \text {leu } m t l-1\end{array}$ & Invitrogen, Carlsbad, CA, U.S.A. \\
\hline $\mathrm{C} 2110$ & $\mathrm{PolA}^{\mathrm{TS}} \mathrm{Nal}^{\mathrm{r}}$ & Kahn and Hanawalt 1979 \\
\hline Pseudomonas fluorescens 55 & $\mathrm{Nal}^{\mathrm{r}}$ & M. Sasser \\
\hline DC3000 & Wild type; spontaneous Rif ${ }^{\mathrm{r}}$ & Cuppels 1986 \\
\hline DC3000 hrcC & hrcC mutant defective in T3SS, $\mathrm{Cm}^{\mathrm{r}}$ & Yuan and He 1996 \\
\hline UNL143 & DC3000 fliR $h r c C$ double mutant, $\mathrm{Cm}^{\mathrm{r}} \mathrm{Sp}^{\mathrm{r}}$ & This work \\
\hline pBluescript-II KS+ & Cloning vector, $\mathrm{Ap}^{\mathrm{r}}$ & Stratagene, La Jolla, CA, U.S.A. \\
\hline pBBR1MCS5 & Broad-host-range vector, $\mathrm{Gm}^{\mathrm{r}}$ & Kovach et al. 1995 \\
\hline pCPP5040 & pML123-hemagglutinin (HA) derivative gateway destination vector, $\mathrm{Gm}^{\mathrm{r}} \mathrm{Cm}^{\mathrm{r}}$ & \\
\hline pCPP5063 & pCPP5040 derivative carrying hopAM1, $\mathrm{Gm}^{\mathrm{r}}$ & Jamir et al. 2004 \\
\hline pCPP5068 & pCPP5040 derivative carrying hop X1, $\mathrm{Gm}^{\mathrm{r}}$ & Jamir et al. 2004 \\
\hline pCPP5100 & pCPP5040 derivative carrying hopK1, $\mathrm{Gm}^{\mathrm{r}}$ & Jamir et al. 2004 \\
\hline pENTR/D-TOPO & Gateway system entry vector, $\mathrm{Km}^{\mathrm{r}}$ & Invitrogen. Carlsbad, CA, U.S.A. \\
\hline pHIR11 & Cosmid pLAFR3 derivative carring genomic DNA of $P$. syringae pv. syringae $61, \mathrm{Tc}^{\mathrm{r}}$ & Huang et al. 1988 \\
\hline pML123 & Broad-host-range cloning vector, $\mathrm{Gm}^{\mathrm{r}} \mathrm{Km}^{\mathrm{r}}$ & Labes et al. 1990 \\
\hline pRK415 & Broad-host-range vector, unstable in absence of selection, $\mathrm{Tc}^{\mathrm{r}}$ & Keen et al. 1988 \\
\hline pVSP61::avrRpm1 & pVSP61 derivative carrying avrRpm $1, \mathrm{Km}^{\mathrm{r}}$ & Mackey et al. 2002 \\
\hline pLN50 & pML123 derivative carrying hopC1-flag, $\mathrm{Gm}^{\mathrm{r}}$ & Jamir et al. 2004 \\
\hline pLN130 & pML123 derivative carrying hopAOl-ha, $\mathrm{Gm}^{\mathrm{r}}$ & Espinosa et al. 2003 \\
\hline pLN150 & pML123 derivative carrying hopH1-flag, $\mathrm{Gm}^{\mathrm{r}}$ & Jamir et al. 2004 \\
\hline pLN162 & pML123 derivative carrying hopE1-flag, $\mathrm{Gm}^{\mathrm{r}}$ & Jamir et al. 2004 \\
\hline pLN164 & pML123 derivative carrying hopAF1-flag, $\mathrm{Gm}^{\mathrm{r}}$ & Jamir et al. 2004 \\
\hline pLN165 & pML123 derivative carrying hopAD1-flag, $\mathrm{Gm}^{\mathrm{r}}$ & Jamir et al. 2004 \\
\hline pLN167 & pML123 derivative carrying hopD1-flag, $\mathrm{Gm}^{\mathrm{r}}$ & Jamir et al. 2004 \\
\hline pLN223 & pML123 derivative carrying hopU1-flag, $\mathrm{Gm}^{\mathrm{r}}$ & Petnicki-Ocwieja et al. 2002 \\
\hline pLN256 & pML123 derivative carrying hopT1-1-flag, $\mathrm{Gm}^{\mathrm{r}}$ & Guo et al. 2005 \\
\hline pLN271 & pML123 derivative carrying hopB1-flag, $\mathrm{Gm}^{\mathrm{r}}$ & Jamir et al. 2004 \\
\hline pLN347 & pML123 derivative containing avrPtoB-ha, $\mathrm{Gm}^{\mathrm{r}}$ & Jamir et al. 2004 \\
\hline pLN452 & pLN615 derivative containing hopS2, $\mathrm{Gm}^{\mathrm{r}}$ & Guo et al. \\
\hline pLN460 & pML123 derivative carrying hopG1-flag, $\mathrm{Gm}^{\mathrm{r}}$ & Jamir et al. 2004 \\
\hline pLN462 & $\begin{array}{l}\text { pPZP212 derivative gateway destination binary vector containing } 35 \text { S promoter and } \\
\text { a HA tag for C-terminal fusions, } \mathrm{Sp}^{\mathrm{r}}\end{array}$ & Jamir et al. 2004 \\
\hline pLN517 & pML123 derivative carrying shcV/hopV1-ha, $\mathrm{Gm}^{\mathrm{r}}$ & Jamir et al. 2004 \\
\hline pLN518 & pML123 derivative carrying hopQ1-1-flag, $\mathrm{Gm}^{\mathrm{r}}$ & This work \\
\hline pLN525 & pLN462 derivative carrying $h o p F 2, \mathrm{Sp}^{\mathrm{r}}$ & $\begin{array}{l}\text { Jamir et al. } 2004 \\
\quad \text { (continued on following page })\end{array}$ \\
\hline
\end{tabular}

\footnotetext{
${ }^{\mathrm{a}} \mathrm{Nal}^{\mathrm{r}}, \mathrm{Rif}^{\mathrm{r}}, \mathrm{Cm}^{\mathrm{r}}, \mathrm{Sp}^{\mathrm{r}}, \mathrm{Ap}^{\mathrm{r}}, \mathrm{Gm}^{\mathrm{r}}, \mathrm{Km}^{\mathrm{r}}$, and $\mathrm{Tc}^{\mathrm{r}}=$ resistant to nalidixic acid, rifampicin, chloramphenicol, spectinomycin, ampicillin, gentamycin, kanamycin, and tetracycline.
} 
urgency to identify specific plant targets and sites of action for type III effectors. We are pursuing a line of experimentation to do this for several of the type III effectors demonstrated to suppress plant immunity. The identification of plant targets for type III effectors promises to reveal key strategies for bacterial pathogenesis and important undiscovered components of innate immunity.

\section{MATERIALS AND METHODS}

Bacterial strains, plasmids, and growth conditions.

The bacterial strains and DNA constructs are listed in Table 2. E. coli and Agrobacterium strains were grown in Luria-Bertani (LB) medium at 37 and $30^{\circ} \mathrm{C}$, respectively, with the appropriate antibiotics. Pseudomonas strains were cultured in King's B (KB) medium at $30^{\circ} \mathrm{C}$ with antibiotics. The concentrations $\left(\mu \mathrm{g} \mathrm{ml}^{-1}\right)$ of antibiotics used in the experiments are as follows: ampicillin, 100; rifampicin, 100; kanamycin, 50; tetracycline, 20; spectinomycin, 50; gentamicin, 10; and nalidixic acid, 100.

\section{DNA manipulation.}

Restriction enzymes, T4 DNA ligase, and Taq DNA polymerase were purchased from New England Biolabs (Beverly, MA, U.S.A.). Thermostable $P f u$ DNA polymerase (Stratagene, La Jolla, CA, U.S.A.) was used to amplify DNA fragments for cloning. Primers listed in Table 3 were ordered from Integrated DNA Technologies (Coralville, IA, U.S.A.). For Gateway cloning, target DNA fragments were amplified by polymerase chain reaction (PCR) using $P f u$ DNA polymerase and were cloned into pENTR/D-TOPO (Invitrogen, Carlsbad, CA, U.S.A.) following the manufacturer's instructions. pENTR constructs were recombined with Gateway Destination vectors by LR reactions using LR Clonase purchased from Invitrogen.

For construction of pLN1965, which lacks the shcA/hopAl operon, a 2.3-kb DNA fragment upstream of $s h c A$ was amplified by PCR from pHIR11, using primers P1892 and P0023, and was cloned into the $X b a \mathrm{I}$ and EcoRI sites of pBluescript $\mathrm{KS}^{+}$, resulting in construct pLN1949. Primers P0227 and P0228 were used to PCR-amplify a 1.5 -kb DNA region downstream of hopAl from pHIR11, and the amplified product was cloned into the XhoI and KpnI sites of pLN1949 resulting in construct pLN1952. An omega cassette containing a spectinomycin-resistant gene was isolated from pHP45 by digestion with EcoRI and was cloned into pLN1952 at the EcoRI site within pLN1952, resulting in pLN1954, which was electroporated into E. coli $\mathrm{C} 2110$ (pHIR11). The resulting strain was grown in LB medium containing tetracycline and spectinomycin at $30^{\circ} \mathrm{C}$, which was then switched to $37^{\circ} \mathrm{C}$ for selection of recombination events. The pHIR11 derivatives that had undergone marker exchange were selected for based on spectinomycin resistance and ampicillin sensitivity and were confirmed

Table 2. (continued from previous page)

\begin{tabular}{|c|c|c|}
\hline Strain or plasmid & Characteristics $^{\mathrm{a}}$ & Reference or source \\
\hline pLN567 & pML123 derivative carrying hopT1-2-flag, $\mathrm{Gm}^{\mathrm{r}}$ & Guo et al. 2005 \\
\hline pLN592 & pLN462 derivative carrying hopAOI, $\mathrm{Sp}^{\mathrm{r}}$ & Espinosa et al. 2003 \\
\hline pLN615 & $\begin{array}{l}\text { pML123 derivative gateway destination vector containing a HA tag for C-terminal } \\
\text { fusions, } \mathrm{Gm}^{\mathrm{r}} \mathrm{Cm}^{\mathrm{r}}\end{array}$ & This work \\
\hline pLN677 & $\begin{array}{l}\text { pBBR1MCS5 derivatived gateway destination vector containing a HA tag for C- } \\
\text { terminal fusions, } \mathrm{Gm}^{\mathrm{r}} \mathrm{Cm}^{\mathrm{r}}\end{array}$ & Petnicki-Ocwieja et al. 2005 \\
\hline pLN682 & pLN677 derivative carrying hopE1, $\mathrm{Gm}^{\mathrm{r}}$ & This work \\
\hline pLN683 & pLN677 derivative carrying $s h c F / h o p F 2$ operon, $\mathrm{Gm}^{\mathrm{r}}$ & This work \\
\hline pLN685 & pLN677 derivative carrying avrPtoB, $\mathrm{Gm}^{\mathrm{r}}$ & This work \\
\hline pLN686 & pLN677 derivative carrying hopAM1, $\mathrm{Gm}^{\mathrm{r}}$ & This work \\
\hline pLN687 & pLN677 derivative carrying hop $X 1, \mathrm{Gm}^{\mathrm{r}}$ & This work \\
\hline pLN734 & pLN1636 derivative containing a $2.0 \mathrm{~kb}$ downstream region of fliR. $\mathrm{Ap}^{\mathrm{r}} \mathrm{Sp}^{\mathrm{r}}$ & This work \\
\hline pLN745 & pLN734 derivative containing a $1.5 \mathrm{~kb}$ upstream region of $f l i R . \mathrm{Ap}^{\mathrm{r}} \mathrm{Sp}^{\mathrm{r}}$ & This work \\
\hline pLN746 & $\begin{array}{l}\text { pRK415 derivative containing a } 1.5 \mathrm{~kb} \text { upstream region, a } \mathrm{Sp}^{\mathrm{r}} \Omega \text { cassette, and a } 2.0-\mathrm{kb} \\
\text { downstream of } f l i R, \mathrm{Tc}^{\mathrm{r}} \mathrm{Sp}^{\mathrm{r}}\end{array}$ & This work \\
\hline pLN1154 & pLN615 derivative carrying hopRl, $\mathrm{Gm}^{\mathrm{r}}$ & This work \\
\hline pLN1156 & pLN615 derivative carrying shcM/hopM1, $\mathrm{Gm}^{\mathrm{r}}$ & This work \\
\hline pLN1323 & pLN615 derivative carrying shcA/hopAl from DC3000, $\mathrm{Gm}^{\mathrm{r}}$ & This work \\
\hline pLN1324 & pLN615 derivative carrying $s h c N / h o p N 1, \mathrm{Gm}^{\mathrm{r}}$ & This work \\
\hline pLN1326 & pLN615 derivative carrying hopAAl-1, $\mathrm{Gm}^{\mathrm{r}}$ & This work \\
\hline pLN1327 & pLN615 derivative carrying avrPtol, $\mathrm{Gm}^{\mathrm{r}}$ & This work \\
\hline pLN1328 & pLN615 derivative carrying hopAS1, $\mathrm{Gm}^{\mathrm{r}}$ & This work \\
\hline pLN1329 & pLN615 derivative carrying hopAN1, $\mathrm{Gm}^{\mathrm{r}}$ & This work \\
\hline pLN1331 & pLN615 derivative carrying hopAQ1, $\mathrm{Gm}^{\mathrm{r}}$ & This work \\
\hline pLN1419 & pLN615 derivative carrying $h o p A A l-2, \mathrm{Gm}^{\mathrm{r}}$ & This work \\
\hline pLN1420 & pLN615 derivative carrying $s h c F / h o p F 2, \mathrm{Gm}^{\mathrm{r}}$ & This work \\
\hline pLN1528 & pLN615 derivative carrying hop $Y 1, \mathrm{Gm}^{\mathrm{r}}$ & This work \\
\hline pLN1622 & pLN615 derivative carrying shcO/hopO1-1, $\mathrm{Gm}^{\mathrm{r}}$ & This work \\
\hline pLN1623 & pLN615 derivative carrying shcO/hopOl-2, $\mathrm{Gm}^{\mathrm{r}}$ & This work \\
\hline pLN1624 & pLN615 derivative carrying shcS2/hopS2, $\mathrm{Gm}^{\mathrm{r}}$ & This work \\
\hline pLN1636 & pBluescript KS- containing Sp resistance $\Omega$ cassette at Hind III site. $\mathrm{Ap}^{\mathrm{r}} \mathrm{Sp}^{\mathrm{r}}$ & This work \\
\hline pLN1906 & pDSK509 derivative carrying avrRpt2, $\mathrm{Km}^{\mathrm{r}}$ & This work \\
\hline pLN1949 & $\begin{array}{l}\text { pBluescript II KS+ derivative carrying a } 2.3 \text {-kb fragment upstream of } s h c A \text { in } \\
\text { pHIR } 11, \mathrm{Ap}^{\mathrm{r}}\end{array}$ & \\
\hline pLN1952 & $\begin{array}{l}\text { pBluescript II KS+ derivative carrying both a } 2.3-\mathrm{kb} \text { fragment upstream of } s h c A \text { and } \\
1.5 \mathrm{~kb} \text { fragment downstream of hopAl in pHIR } 11, \mathrm{Ap}^{\mathrm{r}}\end{array}$ & This work \\
\hline pLN1954 & $\begin{array}{l}\text { pBluescript-II KS+ derivative carrying both a } 2.3-\mathrm{kb} \text { fragment upstream of } s h c A \text {, an } \\
\text { omega Sp resistant gene cassette, and 1.5-kb fragment downstream of hopAl in } \\
\text { pHIR11, } \mathrm{Ap}^{\mathrm{r}} \mathrm{Sp}^{\mathrm{r}}\end{array}$ & This work \\
\hline pLN1965 & $\begin{array}{l}\text { pHIR11 derivative containing a deletion of } s h c A / h o p A l \text { operon that is replaced with } \\
\text { Sp resistant gene cassette, } \mathrm{Tc}^{\mathrm{r}} \mathrm{Sp}^{\mathrm{r}}\end{array}$ & This work \\
\hline pLN2423 & pLN615 derivative carrying avrE1, $\mathrm{Gm}^{\mathrm{r}}$ & This work \\
\hline
\end{tabular}


using PCR and digestion with restriction enzymes. One of these derivatives that lacked shcA/hopAl and contained the spectinomycin omega cassette was designated pLN1965. This construct was introduced into $P$. fluorescens 55 by triparental mating.

\section{Construction of a DC3000 fliR hrcC double mutant.}

We used homologous recombination to delete the fliR gene in the DC3000 hrcC mutant. To do this, a 2.0-kb downstream region of fliR was amplified with primers P1070 and P1071 and was cloned into pLN1636 in the XhoI and KpnI restriction enzyme sites resulting in pLN734. A $1.5-\mathrm{kb}$ upstream region of fliR was amplified with primers P1080 and P1081 and was cloned into pLN734 in the BamHI and EcoRV sites resulting in construct pLN745. A fragment containing the fliR flanking regions with an $\Omega$ fragment between them was cut out using XhoI and EcoRV and was cloned into pRK415, resulting in construct pLN746. pLN746 was transformed into the DC3000 $h r c C$ mutant by electroporation. Homologous recombination in the $f l i R$ region was selected using spectinomycin and screening for loss of tetracycline resistance by growing a DC3000 $h r c C$ (pLN746) culture for 5 days. Each day a new culture was inoculated using the fresh overnight culture in $\mathrm{KB}$ medium containing spectinomycin. The DC3000 fliR hrcC mutant, designated UNL142, was confirmed using PCR.

\section{Protein manipulation and immunoblots.}

Leaf disks of transgenic and wild-type plants were harvested with a $0.64-\mathrm{cm}^{2}$ cork borer and were ground in liquid nitrogen. The ground tissues were resuspended with $100 \mu$ of $1.5 \times$ sodium dodecyl sulfate (SDS) sample buffer, followed by centrifugation for $5 \mathrm{~min}$ at 14,000 rpm. The decanted supernatant was subjected to SDS-polyacrylamide gel electrophoresis. The proteins were transferred to PVDF (polyvinylidene difluoride) membranes (Milipore, Billerica, MA, U.S.A.). Anti-HA primary antibodies (Roche, Basal, Switzerland) were used to detect HA fusion proteins bound on PVDF membranes. Secondary antibodies used in immunoblots were anti-rat immunoglobulin $\mathrm{G}$ alkaline-phosphatase conjugates (Sigma Chemical Co., St. Louis). Proteins on immunoblots were visualized using the CDP-Star chemiluminescence detection kit (Tropix, Bedford, MA, U.S.A.) followed by autoradiography.

\section{Transgenic Arabidopsis plants.}

The Agrobacterium binary constructs pLN592 and pLN525, which constitutively express hopAOl-ha and hopF2-ha, respectively, were electroporated into Agrobacterium tumefaciens $\mathrm{C} 58 \mathrm{C} 1$. The resulting strains were used for Arabidopsis floral-dipping transformation. Transgenic lines were selected on Murashige-Skoog plates for kanamycin resistance. The expression of transgenes was detected by immunoblot using antiHA antibodies. Transgenic plant lines with high and stable expression of HopAO1-HA or HopF2-HA were used in experiments.

\section{Plant HR assay.}

The DC3000 type III effector genes to be tested in P. fluorescens $\mathrm{HR}$ assays were cloned into $\mathrm{pENTR/D-TOPO}$ and were then recombined with pLN615, a pML123 destination vector that expresses C-terminal HA-tagged proteins (Table 2). The resulting constructs were electroporated into $P$. fluorescens (pHIR11). Bacterial strains grown on KB plates were resuspended at $1 \times 10^{8}$ cells $/ \mathrm{ml}$ in $5 \mathrm{mM}$ MES (morpholineethane-

Table 3. Primers for plasmid constructs

\begin{tabular}{|c|c|c|c|}
\hline Gene name & Construct & Primers & Sequence \\
\hline \multirow[t]{2}{*}{ avrE1 } & pLN1098 & P1127 & 5'-CACCACAGAGAGATTAACAGTGCAGTCACCATC-3' \\
\hline & & P1131 & 5'-CTCTTCAGTTCGAACCСCTCTTTCTTCAAG-3' \\
\hline \multirow[t]{2}{*}{ avrPto1 } & pLN307 & P689 & 5'-CACCTGTACTAAAGAGGGTATAAGAATGGGA-3' \\
\hline & & P690 & 5'-TTGCCAGTTACGGTACGGGCT-3' \\
\hline \multirow[t]{2}{*}{ shcA/hopAl } & pLN1028 & P755 & 5'-CACCGTTGATGAGCAGAACAATGAGCAAC-3' \\
\hline & & P758 & 5'-TTTCGTGTTTCGAAGGGCCGG-3' \\
\hline \multirow[t]{4}{*}{ shcA/hopAl } & pLN1965 & $\mathrm{P} 0023$ & 5'-ATGAGAATTCGCATCTCCATGCATCTT-3' \\
\hline & & P0227 & 5'-CGGACTCGAGCTCAGGGCGCGAAACTGA-3' \\
\hline & & P0228 & 5'-GTATGGTACCCCGACCTGGCAACCGCAG-3' \\
\hline & & P1892 & 5'-AGTCTCTAGAGGTGCTATCCACGCAGCG-3' \\
\hline \multirow[t]{2}{*}{ shcF/hopF2 } & pLN536 & P680 & 5'-CACCACCTTAAATTATGAGGATATGAGG-3' \\
\hline & & P682 & 5'-GACCCTTTCGACCGGCACTTT-3' \\
\hline \multirow[t]{2}{*}{ shcM/hopM1 } & pLN1464 & P1108 & 5'-CACCCTCAGAGGCCTAACAATGACCAACAATGACCAG-3' \\
\hline & & P1128 & 5'-ACGCGGGTCAAGCAAGCCCTC-3' \\
\hline \multirow[t]{2}{*}{ shcN/hopN1 } & pLN1070 & P1110 & 5'-CACCAATGAGCGGGGAATAACAATGCGGCCTGTCGAGGCA-3' \\
\hline & & P1129 & 5'-TCGCAAGTGAAAGTCTGCTCTGGGCAC-3' \\
\hline \multirow[t]{2}{*}{ hopR1 } & pLN1133 & $\mathrm{P} 1415$ & 5'-CACCAGGAGTTTAATAATAACGATGGTCAAGG -3' \\
\hline & & P634 & 5'-CACGTTATCGAGTTCGCCCCA-3' \\
\hline \multirow[t]{2}{*}{ hopY1 } & pLN1491 & P1713 & 5'-CACCGCGATAAAGGGAGATGAAACAATGAAC-3' \\
\hline & & P1714 & 5'-CTGGTAGTTGATGCCCGTGGCG-3' \\
\hline \multirow[t]{2}{*}{ hорАA1-1 } & pLN887 & $\mathrm{P} 1230$ & 5'-CACCGAACGAGAGGGAATAACAATGCACATCAAC-3' \\
\hline & & $\mathrm{P} 1231$ & 5'-CGACCGCATAGGCCGAAACGG-3' \\
\hline \multirow[t]{2}{*}{ НорАА1-2 } & pLN888 & P1202 & 5'-CACCGACCGAGATAGAATAACAATGCACATCAACCAATC-3' \\
\hline & & P1203 & 5'-CAAACGCCTGAGCTGAAACGG-3' \\
\hline \multirow{2}{*}{ hopAII } & pLN1011 & P1322 & 5'-CACCCCCATAAACAAAACAATGCTCGC-3' \\
\hline & & $\mathrm{P} 1323$ & 5'-GCGAGTCCAGGGCGGTGGCATCAGC-3' \\
\hline \multirow[t]{2}{*}{ hopAN1 } & pLN1007 & P1314 & 5'-CACCGCGACCGACCTGGCAACAATGCTGGTGC-3' \\
\hline & & $\mathrm{P} 1315$ & 5'-GGCTTCTCCCGCCAATTGCTTGAG-3' \\
\hline \multirow[t]{2}{*}{ hорAQ1 } & pLN1015 & $\mathrm{P} 1310$ & 5'-CACCCAAAGAGGTTTAACAATGAATCGAATTTC-3' \\
\hline & & P1311 & 5'-TGCACTGCCACCAGCAATCGAGCG-3' \\
\hline \multirow[t]{2}{*}{ hopAS1 } & pLN1009 & P1318 & 5'-CACCCGATGGAGCCCAACAATGACCTTAAG-3' \\
\hline & & P1319 & 5'-AGAAAACTCGGCTTTCTGTTCAACC-3' \\
\hline \multirow[t]{4}{*}{$f l i R$} & pLN746 & P1070 & 5'-ATGACTCGAGGCTCGTTGAGATGGCAG A-3' \\
\hline & & P1071 & 5'-ATGAGGTACCTGCTGAAAGATACCGACC-3' \\
\hline & & P1080 & 5'-ATGAGGATCCCACATGCGCCCTGGCGATG-3' \\
\hline & & P1081 & 5'-ATGAGATATCGGTACTGATCTGGATATCGGTCAG-3' \\
\hline
\end{tabular}


sulfonic acid), $\mathrm{pH}$ 5.6; three fivefold serial dilutions were made, and each dilution was infiltrated into Nicotiana tabacum cv. Xanthi leaves side by side with the vector control strain $P$. fluorescens(pHIR11 + pML123). HR responses were recorded 24 to $48 \mathrm{~h}$ after infiltration.

\section{Callose deposition assay.}

To induce callose deposition wild-type $A$. thaliana Col- 0 or transgenic plants were infiltrated with $1 \mu \mathrm{M}$ flg22 or flg $22_{\mathrm{A}_{t}}$ (flg22 from Agrobacterium, which is not recognized by FLS2 in Col-0). Alternatively, they were infiltrated with either the $h r c C$ mutant or the $h r c C$ fliR double mutant. In an additional strategy, we expressed AvrPtoB (pLN685), HopE1 (pLN682), HopF2 (pLN683), HopX1 (pLN687), HopAM1 (pLN686), and pBBR1MCS-5 (vector) in P. fluorescens(pLN1965). The suspensions of the strains were infiltrated into Col-0 at $1 \times 10^{7}$ cells $/ \mathrm{ml}$. For the experiments to determine if the type III effectors suppress callose deposition induced by AvrRpm1, pLN685 (AvrPtoB), pLN682 (HopE1), pLN683 (HopF2), pLN686 (HopAM1), pLN687 (HopX1), and pBBR1MCS-5 were electroporated into $P$. fluorescens(pLN1965) harboring pVSP61::avrRpm1. The resulting strains were infiltrated into A. thaliana Col- 0 at a rate of $1 \times 10^{6}$ cells $/ \mathrm{ml}$. To determine the levels of callose deposition $16 \mathrm{~h}$ after infiltration, leaf samples were cleared with an alcoholic lactophenol solution, followed by a rinse in $50 \%$ ethanol and a rinse in water as described (Adam and Somerville 1996). The completely cleared leaves were stained with $0.01 \%$ (wt/vol) aniline blue in a solution of $150 \mathrm{mM} \mathrm{K} \mathrm{HPO}_{4}$, pH 9.5, for $30 \mathrm{~min}$. The callose deposits were visualized with a fluorescence microscope (Zeiss Axionplan 2, Carl Zeiss, Oberkochen, Germany), and the number of callose deposits was determined using Quantity One software (Bio-Rad, Hercules, CA, U.S.A.).

\section{In planta growth and pathogenicity assays.}

Wild-type A. thaliana Col-0 or transgenic plants were grown in a growth chamber at $24^{\circ} \mathrm{C}$ with $10 \mathrm{~h}$ of light per day. Bacterial growth in Col-0 and transgenic plants was determined by spray-inoculating $A$. thaliana leaves with DC3000 or the DC3000 type III-defective $h r c C$ mutant. In some instances, plants were pretreated with flg22 by infiltration of either $1 \mu \mathrm{M}$ flg22 or $1 \mu \mathrm{M}$ flg22 $2_{A t}$. Plants were spray-inoculated with bacterial suspensions $12 \mathrm{~h}$ after pretreatment. The ability of bacteria to grow in planta was determined as described previously (Espinosa et al. 2003). Briefly, four leaf disks were harvested with a $0.4-\mathrm{cm}^{2}$ cork borer 0 and 4 days after inoculation. The samples were macerated in $250 \mu$ of sterile water for $1 \mathrm{~min}$ and were serially diluted. Each dilution $(20 \mu \mathrm{l})$ was plated on $\mathrm{KB}$ medium containing the appropriate antibiotics. The colonies recovered after $48 \mathrm{~h}$ on plates were enumerated.

\section{ACKNOWLEDGMENTS}

We thank members of the Alfano laboratory for many fruitful discussions and A. Block for reviewing the manuscript. This research was supported by grants from the National Science Foundation (award no. MCB0317165 and MCB-0544447) and the National Institutes of Health (award no. 1R01AI069146-01A2) and funds from the Center for Plant Science Innovation at the University of Nebraska.

\section{LITERATURE CITED}

Abramovitch, R. B., and Martin, G. B. 2005. AvrPtoB: A bacterial type III effector that both elicits and suppresses programmed cell death associated with plant immunity. FEMS (Fed. Eur. Microbiol. Soc.) Microbiol. Lett. 245:1-8.

Abramovitch, R. B., Anderson, J. C., and Martin, G. B. 2006. Bacterial elicitation and evasion of plant innate immunity. Nat. Rev. Mol. Cell Bio. 7:601-611.
Adam, L., and Somerville, S. C. 1996. Genetic characterization of five powdery mildew disease resistance loci in Arabidopsis thaliana. Plant J. 9:341-356.

Alfano, J. R., and Collmer, A. 1997. The type III (Hrp) secretion pathway of plant pathogenic bacteria: Trafficking harpins, Avr proteins, and death. J. Bacteriol. 179:5655-5662.

Alfano, J. R., Bauer, D. W., Milos, T. M., and Collmer, A. 1996. Analysis of the role of the Pseudomonas syringae pv. syringae HrpZ harpin in elicitation of the hypersensitive response in tobacco using functionally nonpolar hrpZ deletion mutants, truncated HrpZ fragments, and hrmA mutations. Mol. Microbiol. 19:715-728.

Alfano, J. R., Kim, H.-S., Delaney, T. P., and Collmer, A. 1997. Evidence that the Pseudomonas syringae pv. syringae hrp-linked hrmA gene encodes an Avr-like protein that acts in an hrp-dependent manner within tobacco cells. Mol. Plant-Microbe Interact. 10:580-588.

Alfano, J. R., Charkowski, A. O., Deng, W., Badel, J. L., Petnicki-Ocwieja, T., van Dijk, K., and Collmer, A. 2000. The Pseudomonas syringae Hrp pathogenicity island has a tripartite mosaic structure composed of a cluster of type III secretions genes bounded by exchangeable effector and conserved effector loci that contribute to parasitic fitness and pathogenicity in plants. Proc. Natl. Acad. Sci. U.S.A. 97:4856-4861.

Ausubel, F. M. 2005. Are innate immune signaling pathways in plants and animals conserved? Nat. Immunol. 6:973-979.

Axtell, M. J., and Staskawicz, B. J. 2003. Initiation of RPS2-specified disease resistance in Arabidopsis is coupled to the AvrRpt2-directed elimination of RIN4. Cell 112:369-377.

Bretz, J. R., Mock, N. M., Charity, J. C., Zeyad, S., Baker, C. J., and Hutcheson, S. W. 2003. A translocated protein tyrosine phosphatase of Pseudomonas syringae pv. tomato DC3000 modulates plant defence response to infection. Mol. Microbiol. 49:389-400.

Chisholm, S. T., Coaker, G., Day, B., and Staskawicz, B. J. 2006. Host-microbe interactions: Shaping the evolution of the plant immune response. Cell 124:803-814.

Collmer, A., Badel, J. L., Charkowski, A. O., Deng, W.-L., Fouts, D. E., Ramos, A. R., Rehm, A. H., Anderson, D. M., Schneewind, O., van Dijk, K., and Alfano, J. R. 2000. Pseudomonas syringae Hrp type III secretion system and effector proteins. Proc. Natl. Acad. Sci. U.S.A. 97:8770-8777.

Cuppels, D. A. 1986. Generation and characterization of Tn5 insertion mutations in Pseudomonas syringae pv. tomato. Appl. Environ. Microbiol. 51:323-327.

de Torres, M., Mansfield, J. W., Grabov, N., Brown, I. R., Ammouneh, H. Tsiamis, G., Forsyth, A., Robatzek, S., Grant, M., and Boch, J. 2006. Pseudomonas syringae effector AvrPtoB suppresses basal defence in Arabidopsis. Plant J. 47:368-382.

Espinosa, A., and Alfano, J. R. 2004. Disabling surveillance: Bacterial type III secretion system effectors that suppress innate immunity. Cell. Microbiol. 6:1027-1040.

Espinosa, A., Guo, M., Tam, V. C., Fu, Z. Q., and Alfano, J. R.2003. The Pseudomonas syringae type III-secreted protein HopPtoD2 possesses protein tyrosine phosphatase activity and suppresses programmed cell death in plants. Mol. Microbiol. 49:377-387.

Fan, F., Ohnishi, K., Francis, N. R., and Macnab, R. M. 1997. The FliP and FliR proteins of Salmonella typhimurium, putative components of the type III flagellar export apparatus, are located in the flagellar basal body. Mol. Microbiol. 26:1035-46.

Felix, G., Duran, J. D., Volko, S., and Boller, T. 1999. Plants have a sensitive perception system for the most conserved domain of bacterial flagellin. Plant J. 18:265-276.

Fujikawa, T., Ishihara, H., Leach, J. E., and Tsuyumu, S. 2006. Suppression of defense response in plants by the avrBs3/pthA gene family of Xanthomonas spp. Mol. Plant-Microbe Interact. 19:342-349.

Gomez-Gomez, L., and Boller, T. 2000. FLS2: An LRR receptor-like kinase involved in the perception of the bacterial elicitor flagellin in Arabidopsis. Mol. Cell 5:1003-11.

Gomez-Gomez, L., Felix, G., and Boller, T. 1999. A single locus determines sensitivity to bacterial flagellin in Arabidopsis thaliana. Plant J. 18:277-284.

Grant, M. R., Godiard, L., Straube, E., Ashfield, T., Lewald, J., Sattler, A., Innes, R. W., and Dangl, J. L. 1995. Structure of the Arabidopsis RPM1 gene enabling dual specificity disease resistance. Science 269 (5225):843-846.

Guo, M., Chancey, S. T., Tian, F., Ge, Z., Jamir, Y., and Alfano, J. R. 2005. Pseudomonas syringae type III chaperones ShcO1, ShcS1, and ShcS2 facilitate translocation of their cognate effectors and can substitute for each other in the secretion of HopO1-1. J. Bacteriol. 187:4257-4269.

Hanahan, D. 1983. Studies on transformation of Escherichia coli with plasmids. J. Mol. Biol. 166:557- 580.

Hauck, P., Thilmony, R., and He, S. Y. 2003. A Pseudomonas syringae type III effector suppresses cell wall-based extracellular defense in sus- 
ceptible Arabidopsis plants. Proc. Natl. Acad. Sci. U.S.A. 100:85778582.

He, S. Y., Huang, H.-C., and Collmer, A. 1993. Pseudomonas syringae pv. syringae harpin ${ }_{\text {Pss }}$ : A protein that is secreted via the Hrp pathway and elicits the hypersensitive response in plants. Cell 73:1255-1266.

Huang, H.-C., Schuurink, R., Denny, T. P., Atkinston, M. M., Baker, C. J. Yucel, I., Hutcheson, S. W., and Collmer, A. 1988. Molecular cloning of a Pseudomonas syringae pv. syringae gene cluster that enables Pseudomonas fluorescens to elicit the hypersensitive response in tobacco plants. J. Bacteriol. 170:4748-4756.

Jamir, Y., Guo, M., Oh, H.-S., Petnicki-Ocwieja, T., Chen, S., Tang, X., Dickman, M. B., Collmer, A., and Alfano, J. R. 2004. Identification of Pseudomonas syringae type III effectors that suppress programmed cell death in plants and yeast. Plant J. 37:554-565.

Jones, J. D., and Dangl, J. L. 2006. The plant immune system. Nature 444:323-329.

Kahn, M. L., and Hanawalt, P. 1979. Size distribution of DNA replicative intermediates in bacteriophage P4 and E. coli. J. Mol. Biol. 128:501525

Keen, N. T., Tamaski, S., Kobayashi, D., and Trollinger, D. 1988. Improved broad-host-range plasmids for DNA cloning in gram-negative bacteria. Gene 70:191-197.

Kim, M. G., da Cunha, L., McFall, A. J., Belkhadir, Y., DebRoy, S., Dangl, J. L., and Mackey, D. 2005. Two Pseudomonas syringae type III effectors inhibit RIN4-regulated basal defense in Arabidopsis. Cell 121:749759 .

Kovach, M. E., Elzer, P. H., Hill, D. S., Robertson, G. T., Farris, M. A., Roop, R. M., and Peterson, K. M. 1995. Four new derivatives of the broad-host-range cloning vector pBBR1MCS, carrying different antibiotic-resistance cassettes. Gene 166:175-176.

Kubori, T., Yamaguchi, S., and Aizawa, S. 1997. Assembly of the switch complex onto the MS ring complex of Salmonella typhimurium does not require any other flagellar proteins. J. Bacteriol. 179:813-817.

Labes, M., Puhler, A., and Simon, R. 1990. A new family of RSF1010-derived expression and $l a c$-fusion broad-host-range vectors for gramnegative bacteria. Gene 89:37-46

Li, X., Lin, H., Zhang, W., Zou, Y., Zhang, J., Tang, X., and Zhou, J. M. 2005. Flagellin induces innate immunity in nonhost interactions that is suppressed by Pseudomonas syringae effectors. Proc. Natl. Acad. Sci. U.S.A. 102:12990-12995

Lindeberg, M., Cartinhour, S., Myers, C. R., Schechter, L. M., Schneider, D. J., and Collmer, A. 2006. Closing the circle on the discovery of genes encoding Hrp regulon members and type III secretion system effectors in the genomes of three model Pseudomonas syringae strains. Mol. Plant Microbe Interact. 19:1151-1158.

Lindeberg, M., Stavrinides, J., Chang, J. H., Alfano, J. R., Collmer, A., Dangl, J. L., Greenberg, J. T., Mansfield, J. W., and Guttman, D. S. 2005. Proposed guidelines for a unified nomenclature and phylogenetic analysis of type III Hop effector proteins in the plant pathogen Pseudomonas syringae. Mol. Plant-Microbe Interact. 18:275-282.

Mackey, D., Holt, B. F., III, Wiig, A., and Dangl, J. L. 2002. RIN4 interacts with Pseudomonas syringae type III effector molecules and is required for RPM1-mediated resistance in Arabidopsis. Cell 108:743-754.

Mackey, D., Belkhadir, Y., Alonso, J. M., Ecker, J. R., and Dangl, J. L. 2003. Arabidopsis RIN4 is a target of the type III virulence effector AvrRpt2 and modulates RPS2-mediated resistance. Cell 112:379-389.

Nurnberger, T., Brunner, F., Kemmerling, B., and Piater, L. 2004. Innate immunity in plants and animals: Striking similarities and obvious differences. Immunol. Rev. 198:249-266.
Oh, H. S., and Collmer, A. 2005. Basal resistance against bacteria in Nicotiana benthamiana leaves is accompanied by reduced vascular staining and suppressed by multiple Pseudomonas syringae type III secretion system effector proteins. Plant J. 44:348-359.

Petnicki-Ocwieja, T., van Dijk, K., and Alfano, J. R. 2005. The hrpK operon of Pseudomonas syringae pv. tomato DC3000 encodes two proteins secreted by the type III (Hrp) protein secretion system: HopB1 and HrpK, a putative type III translocator. J. Bacteriol. 187:649-663.

Petnicki-Ocwieja, T., Schneider, D. J., Tam, V. C., Chancey, S. T., Shan, L., Jamir, Y., Schechter, L. M., Janes, M. D., Buell, C. R., Tang, X., Collmer, A., and Alfano, J. R. 2002. Genomewide identification of proteins secreted by the Hrp type III protein secretion system of Pseudomonas syringae pv. tomato DC3000. Proc. Natl. Acad. Sci. U.S.A. 99:7652-7657.

Rentel, M. C., Leonelli, L., Dahlbeck, D., Zhao, B., and Staskawicz, B. J. 2008. Recognition of the Hyaloperonospora parasitica effector ATR13 triggers resistance against oomycete, bacterial, and viral pathogens. Proc. Natl. Acad. Sci. U.S.A. 105:1091-1096.

Reuber, T. L., and Ausubel, F. M. 1996. Isolation of Arabidopsis genes that differentiate between resistance responses mediated by the RPS 2 and RPM1 disease resistance genes. Plant Cell 8:241-249.

Ritter, C., and Dangl, J. L. 1996. Interference between two specific pathogen recognition events mediated by distinct plant disease resistance genes. Plant Cell 8:251-257.

Rosebrock, T. R., Zeng, L., Brady, J. J., Abramovitch, R. B., Xiao, F., and Martin, G. B. 2007. A bacterial E3 ubiquitin ligase targets a host protein kinase to disrupt plant immunity. Nature 448:370-374.

Singer, A. U., Desveaux, D., Betts, L., Chang, J. H., Nimchuk, Z., Grant, S. R., Dangl, J. L., and Sondek, J. 2004. Crystal structures of the type III effector protein AvrPphF and its chaperone reveal residues required for plant pathogenesis. Structure 12:1669-1681.

Sohn, K. H., Lei, R., Nemri, A., and Jones, J. D. 2007. The downy mildew effector proteins ATR1 and ATR13 promote disease susceptibility in Arabidopsis thaliana. Plant Cell 19:4077-4090.

Underwood, W., Zhang, S., and He, S. Y. 2007. The Pseudomonas syringae type III effector tyrosine phosphatase HopAO1 suppresses innate immunity in Arabidopsis thaliana. Plant J. 52:658-672.

van Dijk, K., Tam, V. C., Records, A. R., Petnicki-Ocwieja, T., and Alfano, J. R. 2002. The ShcA protein is a molecular chaperone that assists in the secretion of the HopPsyA effector from the type III (Hrp) protein secretion system of Pseudomonas syringae. Mol. Microbiol. 44:14691481.

van Dijk, K., Fouts, D. E., Rehm, A. H., Hill, A. R., Collmer, A., and Alfano, J. R. 1999. The Avr (effector) proteins HrmA (HopPsyA) and AvrPto are secreted in culture from Pseudomonas syringae pathovars via the Hrp (type III) protein secretion system in a temperature and $\mathrm{pH}$ sensitive manner. J. Bacteriol. 181:4790-4797.

Yuan, J., and He, S.Y. 1996. The Pseudomonas syringae Hrp regulation and secretion system controls the production and secretion of multiple extracellular proteins. J. Bacteriol. 178:6399-6402.

Zipfel, C. 2008. Pattern-recognition receptors in plant innate immunity. Curr. Opin. Immunol. 20:10-16.

Zipfel, C., Robatzek, S., Navarro, L., Oakeley, E. J., Jones, J. D., Felix, G., and Boller, T. 2004. Bacterial disease resistance in Arabidopsis through flagellin perception. Nature 428:764-767.

Zipfel, C., Kunze, G., Chinchilla, D., Caniard, A., Jones, J. D., Boller, T., and Felix, G. 2006. Perception of the bacterial PAMP EF-Tu by the receptor EFR restricts Agrobacterium-mediated transformation. Cell 125:749-760. 